DOI: 10.2478/romneu-2014-0004

\title{
Craniopharyngioma: How to deal with?
}

\author{
Bianca St. Pintea, Zorinela Andrasoni, I.St. Florian \\ Cluj County Emergency Hospital, Department of Neurosurgery
}

\begin{abstract}
Craniopharyngiomas are rare, highly complex tumors with bimodal incidence in the pediatric and adult age groups. In our opinion, depending on the means possible, total microscopic ablation offers the best chance of healing, or at least prolongs the time interval of recurrences.

Objective: The purpose of this paper is to add our surgical experience to in the last 11 years, in the context of the large debate from literature regarding the best therapeutically option concerning
\end{abstract} craniopharyngioma treatments.

Materials and Methods: We performed a retrospective analysis of 42 consecutive patients with craniopharyngioma who underwent surgical resection by one surgeon at the Neurosurgical Department of Cluj-Napoca County Emergency Hospital between January 2002 and December 2012. We perform a systematic review of the published review on goals and techniques associated with selected surgical strategies for the treatment of $\mathrm{CPH}$.

Results: During this period a total of 42 patients with craniopharyngioma were treated in our institution by a single neurosurgeon, representing $12 \%$ from all cases of sellar and parasellar tumors respectively operated in last 11 years.

There is a significant male preponderance. Nine patients were less than 18 years of age at admission. The patient age distribution showed a peak incidence between 10 and 15 years and another between 45 and 50 years. Considering the pediatric and adult populations together, the most common presenting symptom was visual disturbances with $60 \%$ of patients presenting in this manner, followed by severe headache in more than $50 \%$ of cases. Obstructive hydrocephalus occurred in $31 \%$ of cases. Calcifications were seen in $45 \%$ of cases, more frequently in children.

All our cases underwent surgery by transcranial approach; extended frontotemporal, as the first choice, in $57 \%$ of cases. Gross total removal was achieved in over half of cases and near total resection was achieved in $40 \%$ of cases. The most frequent postoperative complications: diabetes insipidus and syndrome of inappropriate antidiuretic hormone secretion. No visual impairment was observed after surgery in the patients with 
normal visions at presentation. Only 3 of cases primarily operated by us recurred, in an interval of one to five years. The mortality rate in our cases treated by transcranial surgery was $2 \%$ in primary cases and $7 \%$ in cases of tumor recurrence.

Conclusions: Radical surgery offers the best chance for cure. Radical surgery is also associated with a higher risk of postoperative morbidity, being the reason for why many neurosurgeons recommend a subtotal resection followed by radiotherapy. In our opinion radical surgery is possible in large majority of the cases, fronto-temporal approach offering the most appropriate way to reach this objective. Every case must be judged with maximal attention based on preoperative neuroimagistic data but decisively, on intraoperative findings.

\section{Introduction}

Craniopharyngiomas are rare, highly complex tumors with bimodal incidence in the pediatric and adult age groups. These dysontogenic tumors are benign histology but with malignant behavior by infiltrative tendency into critical parasellar neurovascular structures, and by tendency to recurrence despite the impression that they were completed resected. [26] Craniopharyngioma, described by Cushing as "one of the most baffling problems which confront the neurosurgeon", account for less than 3\% of all intracranial tumors at adults and 6-7\% from all brain tumors in children. [24, 44]

In recent years there is a large difference of opinion in regards to multimodal treatment of $\mathrm{CPH}$, from intracranial approaches with total tumor resection or subtotal resection followed by radiotherapy, to an endoscopic approach, or a combination of both. In regards to residual tumors of small dimensions, the recent trend is to use of 3-dimensional conformal radiation treatment (3D CRT), stereotactic radiosurgery (SRS), stereotactic radiotherapy (SRT), and intensitymodulated radiation therapy (IMRT). [42] In our opinion, depending on the means possible, total microscopic ablation offers the best chance of healing, or at least prolongs the time interval of recurrences.

\section{Objective}

The purpose of this paper is to add our surgical experience to in the last 11 years, in the context of the large debate from literature regarding the best therapeutically option concerning craniopharyngioma treatments.

\section{Materials and methods}

We performed a retrospective analysis of 42 consecutive patients with craniopharyngioma who underwent surgical resection by one surgeon at the Neurosurgical Department of Cluj-Napoca County Emergency Hospital between January 2002 and December 2012. We discussed the tumor's characteristics that could influence the treatment decision and the choice of the most reliable approach. The postoperative follow-up was done at one and three month when first control 
MRI is also performed. All the patients were followed up every 3 to 6 months in the first year after discharge from the hospital, and mail correspondence and/or telephone interviews were used after one year. We perform a systematic review of the published review on goals and techniques associated with selected surgical strategies for the treatment of $\mathrm{CPH}$.

\section{Results}

From January 2000 to December 2012 a total of 42 patients with craniopharyngioma were treated in our institution by a single neurosurgeon, representing $12 \%$ from all cases of sellar and parasellar tumors respectively 1, 39\% of all tumors (3006 cases) operated in this period. At pediatric age we found that approximately half of all suprasellar tumors are craniopharyngioma, compared with only about $10 \%$ in adults.

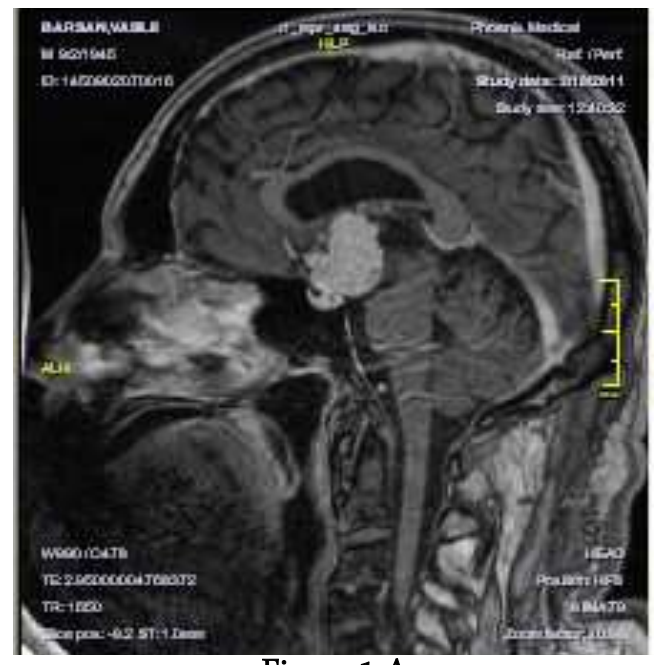

Figure $1 \mathrm{~A}$

Preoperative sagittal contrast- enhanced T1 weighted MRI showed a case of suprasellar solid craniopharyngioma extending from the infudibular area into the third ventricle

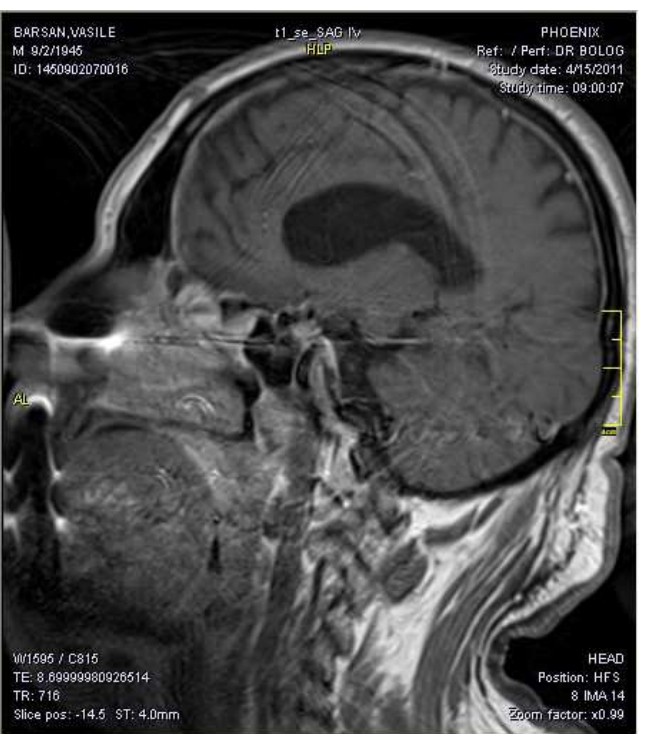

Figure $1 \mathrm{~B}$

Postoperative T1 weighted MRI shows a total removal of the craniopharyngioma by frontotemporal approach
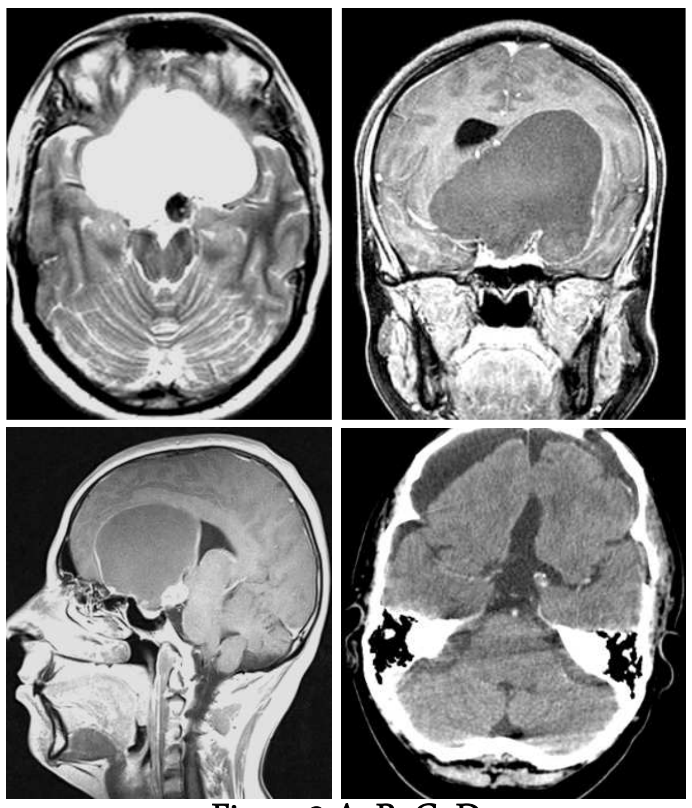

Figure 2 A, B, C, D

Preoperative axial (a), coronal (b) and sagittal (c) T1-weighted MRI showed a giant suprasellar craniopharyngioma with a cystic portion extending into the third ventricle and left lateral ventricle.

Three weeks after operation post-contrast CT scan

(d) showed a small calcified nodule residual 

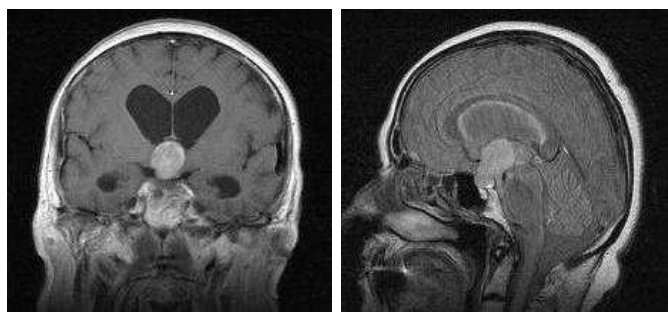

Figure $3 \mathrm{~A}, \mathrm{~B}$

Preoperative sagittal and coronal contrast-enhanced T1 weighted MRI demonstrating a suprasellar tumor with inhomogeneously enhancing solid tumor part

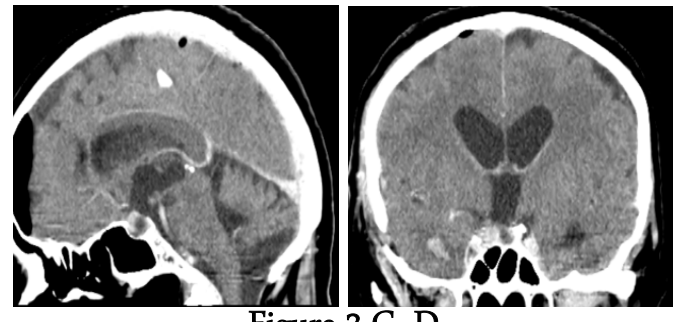

Figure $3 \mathrm{C}, \mathrm{D}$

CT scan at 48 hours after modified right frontotemporal approach. A gross total tumor
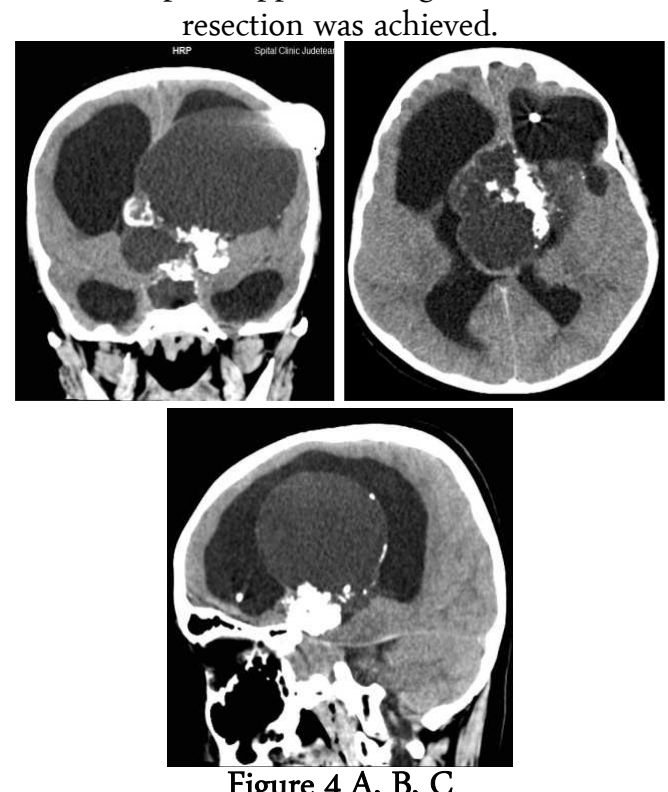

Figure 4 A, B, C

Preoperative coronal, axial and sagittal contrastenhanced T1 weighted MRI demonstrating a giant suprasellar tumor with a large cyst extending in the third ventricle and left lateral ventricle with areas of calcifications and the presence of the Ommaya reservoir.
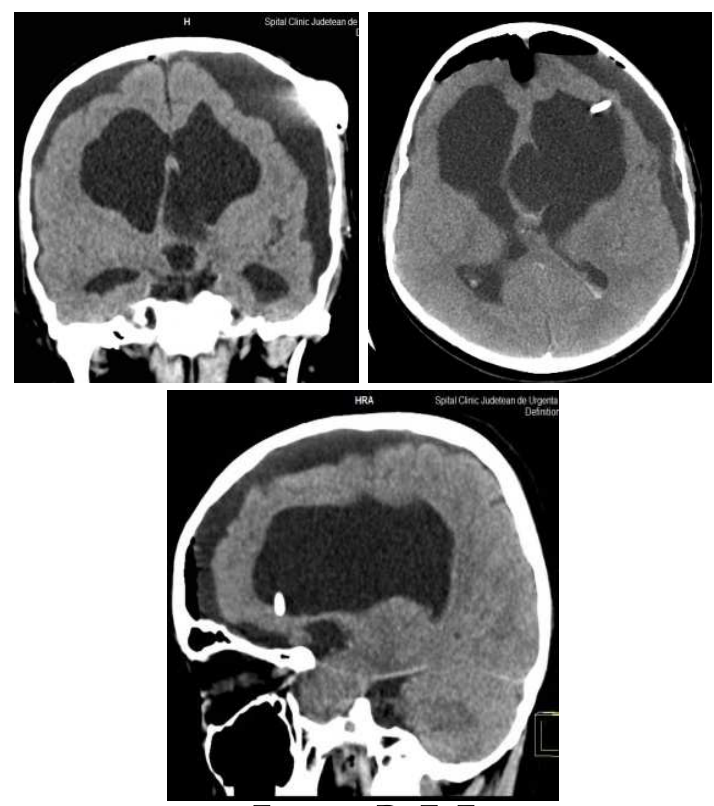

Figure 4 D, E, F

CT scan at 48 hours after modified right

bifrontotemporal approach. A gross total tumor resection was achieved.

There is a significant male preponderance. Of the 42 patients, 24 were males and 18 were females, with a mean age of 27 years (range 4 to 70 years). Nine patients $(22 \%)$ were less than 18 years of age at admission. The patient age distribution showed a peak incidence between 10 and 15 years. Another peak was found between 45 and 50 years. In $17 \%$ of the cases, the histological characteristics of the craniopharyngiomas were of the papillary type and in $83 \%$ of the adamantinomatous type.

Overall the clinical disorders were nonspecific and have included visual deficits, endocrine and behavioral impairments. Considering the pediatric and adult populations together, the most common presenting symptom was visual 
disturbances (visual field defects, decreased visual acuity or visual deterioration), with $60 \%$ of patients presenting in this manner, followed immediately by severe headache in more than $50 \%$ of cases. Neurological symptoms were relatively uncommon. Symptoms related to hydrocephalus, headaches, nausea and vomiting occurred more frequently in children than in adults. In children, the most common presentation was that of growth failure. In adults, hypogonadism was the most common presentation followed by visual deficits and symptoms of raised intracranial pressure. Other less common features include seizures, motor disorders, emotional lability, hallucinations, and precocious puberty, polyuria/polydipsia and weight disorders.

Preoperative work-up tests included computerized tomography (CT) scanning and magnetic resonance imaging (MRI). Obstructive hydrocephalus occurred in 13 (31\%) of cases. Calcifications were seen in 19 (45\%) of cases, more frequently in childhood populations. Predominantly cystic mass was detected in $24 \%$ of cases, partially cystic tumor and solid tumor in the rest of $76 \%$ cases.

All our cases underwent surgery by transcranial approach, extended frontotemporal, as the first choice, in 24 of cases (57\%); we have choose transcallosal interemispheric route or subfrontal interemispheric route by bifrontal approach in 8 of cases (19\%); bifrontopterional craniotomy and combined routes were reserved for multidirectional approach of giant tumors, in $24 \%$ of cases. Four patients $(10 \%)$ had undergone previous surgery in other centers. In one case we have inserted an Ommaya reservoir and we operated the case after 11 years, because of refuse of parents to accept radical intervention. In this particular case we obtain a gross total removal in a single surgical stage, despite the huge dimensions of the tumor. Our intention was gross total resection in all cases and we succeed this in over half of the patients. Near total resection, meaning that a small remnant of tumor capsule or calcified portion of the tumor was left in place because of was a firm adherence to hypothalamus, major calcifications, very thin capsule and adherence to perforating vessels or greater vessels from the polygon of Willis, was achieved in $40 \%$ of our cases. Of all the survival patients the most frequent postoperative complications was diabetes insipidus and syndrome of inappropriate antidiuretic hormone secretion, despite de fact that the preservation of pituitary stalk is one of our goals during the surgery. One of the most difficult problems in the postoperative period was the treatment of hydroelectrolithic disturbances encountered especially in very large tumors. Postoperative endocrine abnormalities were treated by corticosteroids and thyroid hormone replacement. Treatment of long-term hormone deficits varies based on the type of deficiency and it's made by endocrinologist. Visual acuity and visual 
field defects were found in 25 of patients before surgery; in two of them the symptoms was transient aggravated after the operation, while in $12(48 \%)$ patients there was an improvement of vision at 1 month after surgery. No visual impairment was observed after surgery in the patients with normal visions at presentation. Two patients had oculomotor paralysis after the operation, one of them recovered significantly. Among the long-term complications found in our series, we mention: diabetes insipidus with impaired sense of thirst, hypothalamic disturbances with hyperphagia and obesity, the deterioration of cognitive function and excessive daytime sleepiness. Only three of cases primarily operated by us recurred, in an interval of one to five years. Treatment of recurrences is difficult and perioperative morbidity is significantly increased compared to treatment of primary tumor. The operative mortality rate in our cases treated by transcranial surgery was $2 \%$ in primary cases and $7 \%$ in cases of tumor recurrence.

\section{Discussion}

There is no agreement in regards to the optimal management

of craniopharyngiomas; there are proponents to aggressive total surgical resection, when others are in favor of partial resection followed by radiotherapy. The natural history of these lesions is not fully known yet. Surgical resection is the mainstay of definitive treatment and it is the most effective in order to prevent recurrences.
Skull base approaches described for the excision of craniopharyngiomas can be simplified into: anterior midline (subfrontal, transsphenoidal); anterolateral (pterional, orbitozygomatic); and intraventricular (transcallosal-transventricu-lar, transcortical-transventricular, translamina terminalis) approaches. [2, 10, 21] Since such a variety of surgical approaches exists in the management of these tumors, the experience of the surgical team is extremly important.

From a topographical standpoint, there are two types of craniopharyngiomas: intrasellar, localized in the anterior pituitary gland with extension sometimes even before the optic chiasma, and infundibulotuberian, whose anterior extension to the chiasma is rare; also describing $\mathrm{CPH}$ which develop especially on the floor of the third ventricle. [26, 44]

Histologically, there are two types of $\mathrm{CPH}$ : classic adamantin type, heterogenic, in the most part solid, which is most likely found in children; and a papillary type (scuamos papillary and adamantinomatous). Scuamous papillary is predominantly cystic, found almost exclusively in adults, and seems to have a better prognosis than the adamantin.

Criteria for choosing a surgical approach depends on the origin of the tumor with relation to the diaphragma sellae, enlargement of the sella turcica, the extension of intratumoral cysts, shape and size of the $\mathrm{CPH}$, as well as extension under the pia mater. 
Intraoperative MRIs have proven useful in detecting residual tumor and in obtaining a more radical resection. Although, they can produce false images due to blood which may accumulate intraoperatively, making it difficult to differentiate between intracapsular hemorrhage and residual tumor. [40].

In Hoffman's 1998 opinion [21], which advocated total excision whenever possible and achieve gross total resection in the majority of cases in their series of suprasellar tumors, transcranial surgical approaches indicated for $\mathrm{CPH}$ resection can be classified by:

1. Pterional transsylvian approach: small suprasellar tumors, as well as large intrasellar tumors with suprasellar extension; translaminaterminalis pterional approach for intraventricular tumors.

2. Combined pterional-transcallosal anterior-transventricular approach: large suprasellar tumors with 3 rd ventricle extension.

3. Transcallosal-transventricular

approach: tumors exclusively intraventricular

Our experience is in agreement with the report of Yasargil et al. [56] They point out the crucial role of complete tumor removal rather than risking repeated surgical procedures and/or radiation therapy for tumor recurrences. According to them [56 the pterional (aka frontotemporal) approach is the workhorse for the surgical resection of craniopharyngiomas involving primarily the suprasellar cistern.[56] This exposure is suitable for removing craniopharyngiomas involving the intrasellar, suprasellar, prechiasmatic, and retrochiasmatic regions. This is also the preferred method in patients with a prefixed chiasm, because the tumor can be resected beneath the chiasm. A disadvantage of the pterional approach is the limited view of the contralateral opticocarotid triangle and the contralateral retrocarotid space. [10]

Baskin DS et al studied on 74 patients retrospectively with craniopharyngiomas treated during a 15 year period. They reviewed the radiological appearances, presenting symptoms before and after treatment initiation, surgical approaches and the degree of tumoral resection. Based on this data they concluded that radical subtotal removal followed by radiotherapy is an acceptable treatment for craniopharyngioma. [3]

Broggi believes that the standard pterional approach is still indicated for middle fossa extension of tumors even though the use of the pterional approach decreased in the last decade in favor of less invasive approaches. In case of cystic craniopharyngiomas

cystoventriculostomy/cystocysternostomy may be used. [5]

In Chakrabarti et al 2005's opinion, $[9,11]$ the scope of surgical intervention consists of resecting as much as possible of the tumor from the first intervention, any residual tumor being controlled by radiosurgery, considering that it is easier to accept a subtotal resection than a severe complication. N.Gupta et al suggests that 
in case of pediatric craniopharyngiomas gross total removal is associated with increased rates of endocrinopathies compared with subtotal removal and radiotherapy. $[1,19]$

On the contrary, Fahlbush, [14] in a study of 168 consecutive patients, treated between January 1983 and April 1997, concludes that total tumor removal with condition of avoiding intraoperative hazardous gestures offers favorable results immediately postoperative and a longer time frame until recurrence. Total tumor resection was obtained in $50 \%$ of cases with transcranial approaches and in $85 \%$ by transsphenoidal approaches. The most frequent surgical approach used in his study was a pterional approach in 39\% of cases, followed by transsphenoidal in $23 \%$ of cases, bifrontal interemispherical approach being reserved for large retrochiasmatic craniopharyngiomas. So authors recommended the pterional transsylvian approach in all situations where the optic chiasm is postfixed but, if required, the these approach also allows access to the inferior anterior third ventricle through the lamina terminalis.

In a large study of 284 patients with $\mathrm{CPH}$ which were treated exclusively by transcranial approaches by Shi Xang et al, [48] the pterional approach was chosen in 191 cases, due to the inferior or superior location of the tumor in relation to the floor of third ventricle. They consider that preserving the integrity of the hypothalamic structures, the perforating artery of the the pituitary gland being possible by choosing an optimal approach based on the relation of the tumor to the floor of the 3rd ventricle.

In the period from 2001-2011, 66 patients with giant craniopharyngiomas were operated on at the International Neuroscience Institute in Hannover, via the frontolateral approach. The resection was confirmed using intraoperative MRI or early postoperative MRI in some cases. The authors conclude that frontolateral approach allows safe and radical removal even of giant or extensive craniopharyngiomas; hidden parts can be examined with an angled endoscope. [18]

On the contrary, J. C. FernandezMiranda, E. W. Wang et al [30] studied on 55 patients retrospectively with craniopharyngiomas admitted at Neurosurgery Department of Pittsburgh Medical Center (42 with primary craniopharyngiomas and 13 with recurrent). They present that total or near total ( $>95 \%$ of tumor) resection was achieved in $66.6 \%$ of cases by endoscopic endonasal surgery. Recurrence occurred in 18 patients $(32.7 \%)$, and they were treated with repeat surgery or radiosurgery. Based on this data they concluded that this approach provides good results comparable with traditional approaches. [30]

In case of pediatric craniophryngiomas opinions varies depending on patients age. At Center for Endoscopic Skull Base Surgery, Bologna, Italy, endoscopic endonasal surgery has become the approach of choice for midline pediatric craniopharyngiomas, in patients older than 
13 years with gross total removal in majority of cases and without signs of hypothalamic compromising. [16]

Michael L.Levy, in his study on 54 cases of pediatric craniopharyngiomas concludes that the best approach is the one who provides optimum exposure to maximize the chances for total resection, even combined surgical approaches.

Besides classic frontopterional approaches, neuroendoscopic procedures are becoming more popular in the neurosurgical treatment of craniopharyngioma. Typically, transsphenoidal approaches were reserved for sellar tumors and for those with suprasellar extension if the sella turcica appears enlarged, but even in "hourglass" tumors, more so if suprasellar extension is round and symmetrical. [11, 14] Presently, the indications of this approach have expanded including suprasellar tumors with normal dimensions, introducing another two types of transsphenoidal approaches: transsellar-transdiaphragmatic and presellar-tubercular. [27, 29] In 1990, Yasargil used this approach in $9.7 \%$ of 144 cases studied, Van Effentere in just 8\%, and Maira in his 2004 study declares 63\% of cases confirmed a complete $\mathrm{CPH}$ resection by a transsphenoidal approach. [35, 53, 56] In Fahlbush opinion [14] transsphenoidal surgery has the great advantage of not disturbing hypothalamic function.

In a study conducted by Shozo Y.et al [49] 90 patients with craniopharyngiomas were evaluated prospectively at
Department of the Hypothalamic and Pituitary Surgery Tokyo and treated by transsphenoidal surgery or extended transsphenoidal surgery; total removal was achieved in $77,8 \%$ of cases, including supradiaphragmatic type, with a good outcome. According to the authors dural fascia graft is a very effective technique to prevent CSF leaks in this cases. [49]

Regarding the management of intradural bleeding during the extended transsphenoidal surgery Cappabianca's opinion is that the thrombin- gelatin topical haemostatic could be a valuable tool when other strategies to stops bleeding, at the level of superior intercavernous sinus are ineffective, even the ones with high- flow. [7]

Craniopharyngiomas have a tendency to recur even after apparent total resection and radiation therapy. [54] Literature reports between 0 to $50 \%$. Recurrence rates of craniopharyngiomas even after aggressive surgical resection reported by Yasargil in his study was of $7 \%$; [56] Backland in his 1994 study regarding recurrence rates in a large time interval came to the conclusion that it can reach $50 \%$. [2] There are also some cases reported of ectopic recurrences, at a distance of the tumor location as well as the surgical path. [34]. Treatment options for recurrent craniopharyngioma include repeat surgery, radiotherapy and intracystic bleomycin therapy.

The most consistently reported feature predictive for recurrence of craniopharyngioma is the extent of 
resection at initial surgery as well the tumor diameter greater than $4 \mathrm{~cm}$ to $5 \mathrm{~cm}$; extrasellar extension; extension into the third ventricle; the degree of tumor adhesion; hydrocephalus and tumors with greater than $10 \%$ calcification.[ $12,13,19$, 24, 48, 56]. Matson and Crigler, in 1969, postulated that "total excision must be attempted at the first operation" [37]

Radiation therapy is a reference point in the therapeutic management of craniopharyngioma. Today less radical surgery in combination with radiation therapy is favored achieving a progressionfree survival between 70 and 90\%. [14, 52]

The major advantage of proton therapy is the high degree of dose conformity to the target. Beltran et al, [4] retrospectively evaluated proton treatment plans with IMRT plan. He concluded that compared with photon IMRT proton therapy has the potential to significantly reduce whole brain and body irradiation. Retrospective evaluation of outcomes in 15 patients with craniopharyngioma treated with a mix of photon and protons by Fitzek et al. reveals that the tumor control rates at 5 and 10 years were 93 and 85\%, respectively. [15]

Stereotactic instillations of radioisotopes represent in the last period an alternative therapeutic option, for monocystic craniopharyngioma recurrences. Though, this treatment method is restricted to cystic childhood craniopharyngioma and should be considered only for postoperative recurrences and after percutaneous irradiation. $[25,50]$
In opinion of Voges and Hasegawa [20, 55], response rates and cyst controls can be achieved in more than $80 \%$ case of cystic craniopharyngiomas after intracavitary application of different isotopes such as Rhenium186, Yttrium90, or Phosporus32.

Researchers are studying several theories about the radiosurgery and conclude that tumor control is inferior to fractionated treatments and might carry the risk for optic neuropathies unless only smaller lesions are treated away from the optic apparatus. [39, 51]

Bleomycin, an antineoplastic antibiotic that interferes with DNA production, was first introduced in cystic $\mathrm{CPH}$ treatment by Takahasi in 1985. Intracystic administration by stereotactic techniques determines a decrease in intracystic fluid secretion and favors tumor cell degeneration. In recent years the routine use of Bleomycin has been decreased due to a series of complications reported such as occlusive vasculopathy, pulmonary fibrosis, bilateral hypoacusis, hypersomnia, thermal disfunction. [45,46]. Recent reports on the effect and tolerability of intracystic instillation of interferon $\alpha$ are promising [23]

According to Cavalhero et al in their 1996 study, the implantation of an intracystic catheter with a subcutaneous reservoir and instillation of sclerosing substances represent a useful therapeutic method for cystic recurrent tumors whose anatomical configuration and localization make them difficult to resect. $[8,47]$ 
In a study published in 2004, Bricolo and collaborators present therapeutic efficiency of a multimodality stereotactic approach to regrowing/recurrent cystic craniopharyngiomas: neuroendoscopy, intracavitary bleomycin and gamma knife (GK) radiosurgery. [32, 39] Ohata $\mathrm{K}$. et al [41] conclude that "the use of radiosurgery for craniopharyngioma is still a matter of discussion".

\section{Conclusions}

Radical surgery offers the best chance for cure. Radical surgery is also associated with a higher risk of postoperative morbidity, being the reason for why many neurosurgeons recommend a subtotal resection followed by radiotherapy. In our opinion radical surgery is possible in large majority of the cases, fronto-temporal approach offering the most appropriate way to reach this objective. Every case must be judged with maximal attention based on preoperative neuroimagistic data but decisively, on intraoperative findings. Radical surgery could be an objective, but this must not be an objective with every cost, because the cost could be too high. Despite advances in neuroimaging, microsurgical techniques and hormone replacement multimodal treatment, the overall prognosis remains reserved on long term follow-up.

\section{References}

1.Aaron J. Clark, M.D., Ph.D., Tene A. Cage, M.D., Derick Aranda, M.D., Nalin Gupta, M.D., Ph.D, Treatment-related morbidity and the management of pediatric craniopharyngioma. A systematic review.
Journal of Neurosurgery: Pediatrics: Oct 2012 / Vol. 10 / No. 4 / Pages 293-301

2. Backlund EO: Treatment of craniopharyngiomas: the multimodality approach. Pediatr Neurosurg 1994, 21: 82- 89

3.Baskin DS, Wilson CB. Surgical management of craniopharyngiomas. A review of 74 cases. J Neurosurg. 1986 Jul; 65(1):22-7.

4.Beltran, C., Roca, M., and Merchant, T. E. (2011). On the benefits and risks of proton therapy in pediatric craniopharyngioma. Int. J. Radiat. Oncol. Biol. Phys.

5.Broggi M., Castiglione, M., Schiariti, M.; Acerbi, F.; Tringali, G.; Broggi, G.: Twenty Years Experience of Craniopharyngioma Surgery in 111 Cases: The Evolution toward Minimally Invasive Surgery: Journal of Neurological Surgery Part B: Skull Base; Issue S 02, 2012

6.Caldarelli M, Di Rocco C, Papacci F, Colosimo C Jr: Management of recurrent craniopharyngioma. Acta Neurochir (Wien) 140:447-454, 1998

7.Cappabianca P, Esposito F, Esposito I, et al: Use of thrombin- gelatin haemostatic matrix in endoscopic endonasal extended approaches: Technical note. Acta Neurochir 151: 69- 77, 2009

8.Cavalheiro S, Sparapani FV, Franco JO, da Silva MC, Braga FM Use of bleomycin in intratumoral chemotherapy for cystic craniopharyngioma. J Neurosurg 84:124-126,1996

9.Chakrabarti I, Amar A, Couldwell W, et al: Long term neurological visual and endocrine outcomes following transnasal resection of craniopharyngiomas. J.Neurosurg 102: 650- 657, 2005

10.Choux M, Lena G: Craniopharyngioma, in Apuzzo MLJ (ed): Surgery of the Third Ventricle, ed 2. Baltimore: Williams \& Wilkins, 1998, pp 1143-1181 11.Couldwell WT, Weiss MH, Rabb C, et al: Variations on the standard transsphenoidal approach to the sellar region, with emphasis on the extended approaches and parasellar approaches: surgical experience in 105 cases. Neurosurgery 55:539-550, 2004

12.Di Rocco C, Caldarelli M, Tamburrini G, Massimi L: Surgical management of craniopharyngiomasexperience with a pediatric series. J Pediatr Endocrinol Metab 19:355-366, 2006

13. Duff J, Meyer F, et al. Long-term outcomes for surgically resected craniopharyngiomas Neurosurgery, 46 (2000), pp. 291-302 [discussion 302-5]

14.Fahlbusch, R., Honegger, J., Paulus, W., Huk, W., and Buchfelder, M. Surgical treatment of 
craniopharyngiomas: experience with 168 patients. J. Neurosurg. 90, 237-250, 1999

15.Fitzek, M. M., Linggood, R. M., Adams, J., and Munzenrider, J. E. Combined proton and photon irradiation for craniopharyngioma: long-term results of the early cohort of patients treated at Harvard Cyclotron Laboratory and Massachusetts General Hospital. Int. J. Radiat. Oncol. Biol. Phys. 64, 1348-1354, 2006

16.Frank, G.; Mazzatenta, D.; Zoli, M.; Faustini-Fustini, M.; Pasquini, E.Endoscopic Endonasal Surgery in Pediatric Craniopharyngiomas with Suprasellar Extension Journal of Neurological Surgery Part B: Skull Base; Issue S 02, 2012

17.Garnett MR, Puget S, Grill J, Sainte-Rose C: Craniopharyngioma. Orphanet J Rare Dis 2:18, 2007

18.Gerganov, V.; Metwalli, H.; Fahlbusch, R.; Samii, A.; Samii, M.: Surgical Removal of Giant Craniopharyngiomas via the Frontolateral Approach: Operative Technique and Analysis of the OutcomeJournal of Neurological Surgery Part B: Skull Base; Issue S 02, 2012

19.Gupta D.K. , Ojha B.K, Sarkar C. et al. Recurrence in craniopharyngiomas: analysis of clinical and histological features J Clin Neurosci, 13 (2006), pp. 438-442

20.Hasegawa, T., Kondziolka, D., Hadjipanayis, C. G., and Lunsford, L. D. (2004). Management of cystic craniopharyngiomas with phosphorus-32 intracavitary irradiation. Neurosurgery 54, 813-822.

21.Hoffman $\mathrm{H}$ : Surgical management of craniopharyngiomas. In Setti S. Rengachary@ Robert H. Wilkins(eds), Neurosurgical Operative Atlas, AANS 7> 173/ 181, 1999.

22.Hukin J, Steinbok P, Lafay-Cousin L et al: Intracystic bleomycin therapy for craniopharyngioma in children. Cancer 109:2124-2131, 2007

23.Ierardi DF, Fernandes MJ, Silva IR, Thomazini-

Gouveia J, Dastoli P,Cavalheiro S 2007 Apoptosis in $\alpha$ interferon (IFN- $\alpha$ ) intratumoral chemotherapy for cystic craniopharyngiomas. Childs Nerv Syst 23:1041104

24.Isaac MA, Hahn SS, Kim JA et al. Management of craniopharyngioma Cancer J, 7 (2001), pp. 516-520

25.Julow J, Backlund EO, Lányi F, Hajda M, Nyáry I, 2007 Long-term results and late complications after intracavitary yttrium-90 colloid irradiation of recurrent cystic craniopharyngiomas. Neurosurgery 61:288-295; discussion 295-296
26.Karavitaki N, Cudlip S, et al.: Craniopharyngiomas. Endocr Rev 27. 371-397.2006

27.Kato T, Sawamura Y, Abe H, et al: Transsphenoidaltranstuberculum sellae approach for supradiaphragmatic tumors: technical note. Acta Neurochir 140:715-719, 1998

28.Kobayashi T, Kida Y, Mori Y, Hasegawa T: Longterm results of gamma knife surgery for the treatment of craniopharyngioma in 98 consecutive cases. J Neurosurg 103 (6 Suppl):482-488, 2005

29.Kouri JG, Chen MY, Watson JC, et al: Resection of suprasellar tumors by using a modified transsphenoidal approach. Report of four cases. J Neurosurg 92:10281035, 2000

30.Koutourousiou, M.; Paluzzi, A.; Tormenti, M. J..; Fernandez-Miranda, J. C.; Wang, E. W. et al. Endoscopic Endonasal Surgery for Craniopharyngiomas, Journal of Neurological Surgery Part B: Skull Base; Issue S 02, 2012

31.Landolt A M. History of pituitary surgery from the technical aspect. Neurosurg Clin N Am. 2001; 12:3744.

32.Lee, M., Kalani, M. Y., Cheshier, S., Gibbs, I. C., Adler, J. R., and Chang, S. D. (2008). Radiation therapy and CyberKnife radiosurgery in the management of craniopharyngiomas. Neurosurg. Focus 24, E4.

33.Liu JK, Weiss MH, Couldwell WT: Surgical approaches to pituitary tumors. Neurosurg Clin N Am 14:93-107, 2003

34.Liu JM, Garonzic IM, Eberhart CG, et al: Ectopic recurrence of craniopharyngioma after an interhemispheric transcallosal approach: case report. Neurosurgery 50: 639- 645, 2002

35.Maira G, Anite C, Albanese A, et al: The role of transsphenoidal surgery in the treatment of craniopharyngiomas. J Neurosurg 100: 445- 451, 2004 36.Maira G, Anite C, Colosimo C, et al: Craniopharyngiomas of the third ventricle: translamina terminalis approach. Neurosurgery 47: 857- 865, 2000 37.Matson D., Crigler J.: Management of craniopharyngioma in childhood. J Neurosurg 30. 377390.1969

38.Merchant TE, Kiehna EN, Kun LE, Mulhern RK, Sanford RA 2006 Phase II trial of conformal radiation therapy for pediatric patients with craniopharyngioma and correlation of surgical factors and radiation dosimetry with change in cognitive function. J Neurosurg 104(2 Suppl):94-102 39.Minniti, G., Esposito, V., Amichetti, M., and Enrici, R. M. The role of fractionated radiotherapy and 
radiosurgery in the management of patients with craniopharyngioma. Neurosurg. Rev. 32, 125-132, 2009 40.Nimsky C, Ganslandt O, Hofmann B, Fahlbusch R: Limited benefit of intraoperative low-field magnetic resonance imaging in craniopharyngioma surgerz. Neurosurg 53: 72- 81, 2003

41.Ohata K, Kunihieo N, Goto T et al .Role of Skull Base Surgery for Radical Resection of Craniopharyngioma in the Era of RadiosurgeryJournal of Neurological Surgery Part B: Skull Base; Issue S 02, 2012

42.Puget S, Garnett M, Wray A, Grill J, Habrand JL, Bodaert N, Sainte-Rose C 2007 Pediatric craniopharyngiomas: classification and treatment according to the degree of hypothalamic involvement. J Neurosurg 106(1 Suppl):3-12

43.Rajan B, Ashley S, Gorma C, et al: Craniopharyngiomas-long term results following limited surgery and radiotherapy. Radiother Oncol 26:1-10, 1993.

44.Rushing E, Giangaspero F, Paulus $W$ et al. Craniopharyngioma D. Louis, H. Ohgaki, O. Wiestler, W.K. Cavenee (Eds.), WHO classification of tumours of the central nervous system, WHO Press, Geneva (2007), pp. 238-240

45.Sajoh M, Murakami H, Hirase Y, et al: Occlusive cerebrovasculopathy after internal radiation and bleomicin therapy for a craniopharyngioma: case report. Neurol Med Chir (Tokyo) 37: 920- 923, 1997

46.Savas A, Erdem A, Tun K, et al: Fatal toxic effect of bleomycin in brain tissue after intracystic chemotherapy for a craniopharyngioma: case report. Neurosurgery 46 : 213- 217, 2000

47.Schubert T, Trippel M, Tacke U, van Velthoven V, Gumpp V, Bartelt S, et al: Neurosurgical treatment strategies in childhood craniopharyngiomas: is less more? Childs Nerv Syst 25:1419-1427, 2009
48.Shi XE, Wu B, Zhou ZQ, Fan T, Zhang YL: Microsurgical treatment of craniopharyngiomas: report of 284 patients.Chin Med J (Engl) 119:1653-1663, 2006 49.Shozo Yamadaemail, Noriaki Fukuhara, Kenichi Oyama, et al: Surgical Outcome in 90 Patients with Craniopharyngioma: An Evaluation of Transsphenoidal Surgery. World Neurosurgery Volume 74, Issue 2, Pages 320-330, 2010

50.Szeifert GT, Bálint K, Sipos L, Sarker MH, Julow J 2007 Pathological findings in cystic craniopharyngiomas after stereotactic intracavitary irradiation with yttrium90 isotope. Prog Neurol Surg 20:297-302

51.Tishler, R. B., Loeffler, J. S., Lunsford, L. D., Duma, C., Alexander, E. III, Kooy, H. M., and Flickinger, J. C. (1993). Tolerance of cranial nerves of the cavernous sinus to radiosurgery. Int. J. Radiat. Oncol. Biol. Phys. 27, 215-221.

52.Tomita, T., and Bowman, R. M. (2005). Craniopharyngiomas in children: surgical experience at Children's Memorial Hospital. Childs Nerv. Syst. 21, 729-746.

53.Van Effenterre R, Boch AL: Craniopharyngioma in adults and children; a study of 122 surgical cases. J Neurosurg 97:3- 11, 2002

54.Veeravagu $\mathrm{A}$, Lee $\mathrm{M}$, Jiang $\mathrm{BV}$ et al. The role of radiosurgery in the treatment of craniopharyngiomas Neurosurg Focus, 28 (2010), p. E11

55.Voges J, Sturm V, Lehrke R, Treuer, et al. Cystic craniopharyngioma: long-term results after intracavitary irradiation with stereotactically applied colloidal betaemitting radioactive sources. Neurosurgery 40, 263-270. 1997

56.Yaşargil MG, Curcic M, Kis M, Siegenthaler G, Teddy PJ, Roth P: Total removal of craniopharyngiomas. Approaches and long-term results in 144 patients. J Neurosurg 73:3-11, 1990. 